\title{
Design and Analysis of Vertical Axis Wind Turbine for Household Application
}

\author{
Ramesh K. Kavade and Pravin M. Ghanegaonkar
}

\begin{abstract}
A hybrid turbine with combination of Savonius and Darrieus is being investigated in an effort to improve the coefficient of power with same aspect ratio. To achieve this objective, first Savonius turbine is experimentally tested with gap between central shaft and rotor with two blades, three blades and four blades. Tests show that the coefficient of power of three blades rotor is higher than that of the two and four blades at low wind speed. Further the Savonius, Darrieus and modified Hybrid turbines are tested at different wind velocities through wind tunnel. Investigation is carried out to study the effect of geometrical and operational parameters on the performance of a turbine in terms of coefficient of power, coefficient of static torque and coefficient of torque. The modified hybrid turbine gives higher coefficient of power $(0.23)$ at a low wind speed, as compared to that of Savonius rotor $(0.19)$ and Darrieus three blade rotor $(0.21)$. Hence it is proposed to be used for household application for power generation at rural and urban areas. However the parameters of the hybrid turbine need to be optimized to commercialize this turbine.
\end{abstract}

Index Terms-Coefficient of power, hybrid turbine, Renewable energy, vertical axis wind turbine (VWAT), wind energy.

\section{INTRODUCTION}

The vertical axis wind turbine is simple in construction, low cost, self-starting at low wind speed and do not require yaw mechanism. It always orient towards the wind direction. This makes it suitable for generating electrical energy for house hold application at rural and urban areas in many countries especially in India. In recent years, research work is carried out to increase the power coefficient of vertical axis wind turbine. Review of the papers show that, the CFD analysis and experiments are conducted in slow speed wind tunnel on various types of vertical axis wind turbines like Darrieus, H-type, and Savonius. In many research papers, the performance of the turbine is studied and investigated with varying design parameters such as number of blades, profile of blades, aspect ratio, and pitch angle. It is observed the power coefficient of savonius turbine is varies from 0.12 to 0.22 for different operating parameters.

Vertical axis wind turbines are mainly classified in two types; Savonius and Darrieus type. VAWTs mainly useful for house hold application at rural and urban areas such as individual homes, farms or some residential areas as way of

Manuscript received February 25, 2016; revised November 25, 2016.

Ramesh Krishnat Kavade is with Dr. D. Y. Patil Institute of Engineering and Technology, Pimpri, Pune, Maharashtra, India (e-mail: kawade.ramesh@gmail.com).

Pravin M. Ghanegaonkarwas is with the Mechanical Engineering Department, Dr. D. Y. Patil Institute of Engineering and Technology, Pimpri, Pune, Maharashtra, India (e-mail: pmghanegaonkar@yahoo.com). providing personal wind energy. Wind energy is the most potential and economical energy resource compared with conventional energy resources. Wind energy can help in reducing the dependency on fossil fuel. Necessary steps are being taken up across the world to harness the maximum power from wind and its effective utilization in power production for household application. It has been predicted that roughly 10 million MW of wind energy continually available on the surface of earth. India's wind power potential is $45000 \mathrm{MW}$ [1].

S. J. Savonius first developed the vertical axis Savonius rotor in late 1920.This type of turbine generates the electricity through the drag force. The Savonius turbine is developed by cutting cylinder into two equal parts along the central plane and taking two semi cylinder surfaces sideways along the cutting the plane that the cross section resembled the letter ' $\mathrm{S}$ '. The Savonius wind turbine works because of difference in forces exerted on each blade. The drag force on concave face of the cylinder is greater than the drag force on the convex section of blade [2].

Darrieus wind turbine rotors are based on lift force; it was first developed by G. J. Darrieus, a French Engineer in 1925. Darrieus wind rotor has two to three thin curve blades with airfoil cross section profile and constant chord length. Darrieus type wind rotor has many variants, all of which use lift force to rotate the rotor and hence generate electricity. According to Mohammed Hadi Ali, two blades Savonius wind turbine is more efficient and it has higher power coefficient under the same operating condition than that of three blade Savonius wind turbine [3]. Burcin Deda Alten attempted to curtain arrangement as a wind deflector with a simple construction to prevent negative torque that occurs on the convex surface of Savonius rotor [4]. Kamoji et al. observed the effect of the overlap ratio, blade arc angle, and aspect ratio and Reynolds number on the performance of Savonius rotor. They found that, the modified Savonius rotor without overlap ratio, with blade arc angle of $124^{\circ}$ and with an aspect ratio of 0.7 has a maximum power coefficient 0.21 at low wind speed [5]. U. K. Saha conducted test on single, two and three stage Savonius rotor with identical stage aspect ratio and concluded that two stage Savonius rotor perform better than the single stage and three stage Savonius rotor [6]. J. L. Menet presented study on single and double stage Savonius rotor. He used blades from plastic tube (PVC) and steel shaft. He utilized a rotor with aspect ratio of 4 and overlap of 0.25 and the mean coefficient of power between 5 and $10 \mathrm{~m} / \mathrm{s}$ was found to be 0.29 [7]. M. A. Kamoji [8] has tested helical Savonius rotor in an open jet wind tunnel. Coefficient of static torque, coefficient of torque and coefficient of power for each helical Savonius rotor are 
measured and concluded that, the helical rotors with shaft have lower coefficient of power than the helical rotor without shaft. M. Abid, K. S. Karimov have constructed and tested Darrieus wind turbine with 3 blades and reported slow starting at low wind speed. A separate Savonius rotor on the top of an existing Darrieus turbine was mounted to make the turbine self start at low wind speed [9]. Taher G. Abu-El-Yazied created twelve models with different number of blades and blade chord lengths to study their effect on the performance of Darrieus wind turbine using the CFD analysis. The results show increase in blade chord length increases the power coefficient till a certain limit after which power coefficient is considerably decreases due to increase in solidity and decreasing corresponding tip speed ratio [10]. S. Brusca et al. analyzed performance of H-rotor with different aspect ratio and concluded that, H-rotor coefficient of power is better at low aspect ratio [11].

Gupta et al. made a combination between Savonius turbine and Darrieus turbine. They compared the results obtained with those of conventional Savonius rotor. They observed that there is improvement in the power coefficient for the combined Savonius-Darrieus rotor [12].

Robert Howell et al. made combined experimental and computational study into the aerodynamics and performance of a small scale vertical axis wind turbine. The straight turbine rotor blade, with an aspect ratio of 4:1, operates at relatively low tip speeds and its performance shows a clear dependence on the rotor blade surface finish. Performance is enhanced by having the surface of the turbine roughened at a critical Reynolds number 30,000 [13]. Fang Feng combined Savonius rotor with H-rotor and reported that, H-rotor is self-started at low tip speed ratio [14]. According to S. M. Rassoulinejad Mousai Savonius rotor was low efficient but self-started at low speed. On the other hand H-rotor Darrieus is high efficient but not self-started [15].

Present study includes the performance analysis of Savonius turbine with two, three and four blades with cover plate and Darrieus turbine with three and four airfoil blades experimentally. The coefficient of power between modified hybrid turbine, Savonius and Darrieus rotor is determined experimentally and compared.

\section{PERFORMANCE PARAMETERS}

The power in the wind can be computed by using the concepts of kinetics. The wind mill works on the principle of converting kinetic energy of the wind to mechanical energy. 1. Wind power: $\mathrm{Pw}=1 / 2 \rho \mathrm{AV}^{3}$

2. Swept area: $A=D H$

3. Aspect ratio: $\alpha=\frac{\operatorname{RotorHeight}(H)}{\text { RotorDiameter }(D)}$

4. Overlap ratio: $\beta=\frac{e-a}{D}$

5. Actual turbine Power (Mechanical Power):

$P_{t}=\frac{2 \pi N T}{60}$

6. Torque: Torque calculated from measured load and spring balance is given by

$T=(m-s)\left(r_{\text {pully }}+r_{\text {rope }}\right) g$
Where $m$ is the mass loaded on the pan in $\mathrm{kg}, s$ is the spring balance reading in $\mathrm{kg}$ and $g$ is the gravitational acceleration in $\mathrm{k}_{\mathrm{g}} / \mathrm{s}^{2}$

7. Reynolds number: $R_{e}=\frac{\rho V D}{\mu}$,

8. Tip speed ratio: $\lambda=\frac{\omega \mathrm{D}}{2 \mathrm{~V}}$

9. Coefficient of power: $C_{p}=\frac{P m}{1 / 2 \rho A V^{\mathrm{a}}}=\frac{T \omega}{1 / 2 \rho A V^{\mathrm{a}}}$

10. Coefficient of torque: $C_{t}=\frac{T}{1 / 4 \rho A d V^{2}}$

11. Coefficient of static torque: $C_{t s}=\frac{T s}{1 / 4 \rho A d V^{2}}$

\section{TURBINES USED IN THIS STUDY}

In the present work three turbines namely Savonius, Darrieus and Hybrid turbine combined with Savonius and Darrieus are designed, fabricated and tested with wind tunnel for wind speed range $0-12 \mathrm{~m} / \mathrm{s}$. Fig. 1-3 show the tested turbines and various design parameters of these turbines are given in the Tables 1-3.

\begin{tabular}{clc}
\multicolumn{2}{c}{ TABLE I: VARIOUS PARAMETERS OF SAVONIUS TURBINE } \\
\hline Sr. No. & \multicolumn{1}{c}{ Parameters } & Values \\
\hline 1 & Rotor diameter, D (mm) & 600 \\
2 & Rotor height, $\mathrm{H}(\mathrm{mm})$ & 600 \\
3 & Diameter of shaft, $\mathrm{d}_{\mathrm{s}}(\mathrm{mm})$ & 40 \\
4 & Blade diameter, d $(\mathrm{mm})$ & 380 \\
\hline
\end{tabular}
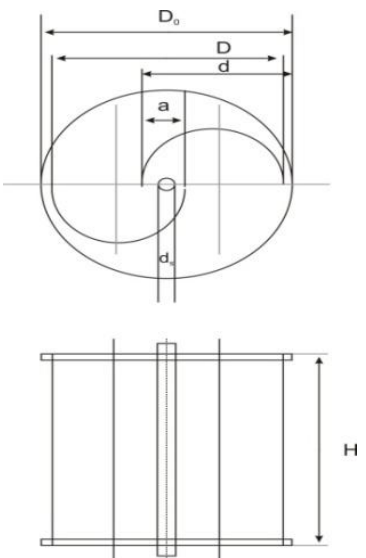

Fig. 1. Savonius turbine with two blades.

TABLE II: VARIOUS PARAMETERS OF DARRIEUS TURBINE

\begin{tabular}{clc}
\hline Sr. No. & \multicolumn{1}{c}{ Parameters } & Values \\
\hline 1 & Blade airfoil & NACA0021 \\
2 & Rotor diameter $(\mathrm{mm})$ & 600 \\
3 & Rotor height $(\mathrm{mm})$ & 600 \\
4 & Chord of blade, $\mathrm{c}(\mathrm{mm})$ & 95 \\
\hline
\end{tabular}

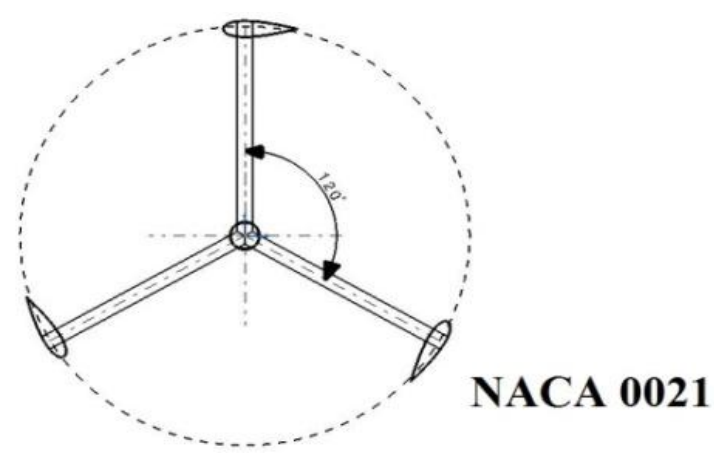

Fig. 2. Darrieus turbine with three aerofoil blade. 
TABLE III: VARIOUS PARAMETERS OF HYBRID TURBINE

\begin{tabular}{clc}
\hline Sr. No. & \multicolumn{1}{c}{ Parameters } & Values \\
\hline 1 & Blade airfoil & NACA0021 \\
2 & Rotor diameter $(\mathrm{mm})$ & 600 \\
3 & Rotor height $(\mathrm{mm})$ & 600 \\
4 & Chord of blade, c $(\mathrm{mm})$ & 95 \\
5 & Savonius blade diameter, $\mathrm{D}_{\mathrm{s}}(\mathrm{mm})$ & 500 \\
6 & Savonius blade heights $(\mathrm{mm})$ & 600 \\
\hline
\end{tabular}

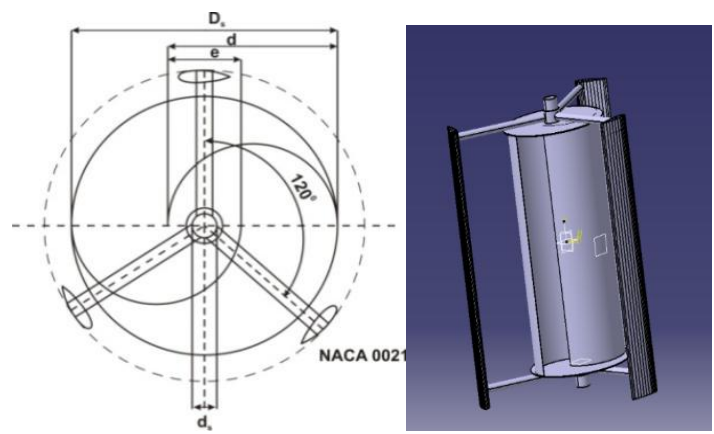

Fig. 3. Hybrid turbine combined with Savonius and Darrieus.

\section{EXPERIMENTAL SET UP AND MEASUREMENT}

Fig. 4 (a) shows the schematic diagram of the experimental set-up which is used in the present work. It consists mainly 1 . Axial fan; 2. Wind tunnel; 3. Ball bearing; 4. Turbine; 5. Steel housing; 6. Spring balance; 7. Pulley and 8. Weighing pan. The test turbines are supported vertically in steel structure as shown in Fig. 4 (b, c, d) and placed $450 \mathrm{~mm}$ downstream the exit section of a wind tunnel such that the axis of rotation is in line with the center of the wind tunnel exit area. The wind tunnel is $750 \mathrm{~mm}$ wide, $600 \mathrm{~mm}$ deep and $4800 \mathrm{~mm}$ long. The axial fan is used to flow air on the test turbine blades and supplies air with range of $0-12 \mathrm{~m} / \mathrm{s}$ at the exit of the wind tunnel. The wind velocity supplied by axial fan is measured at exit of the wind tunnel by using a digital anemometer. The digital tachometer is used to measure the speed of the rotating shaft of the test turbine. A rope brake drum dynamometer is used for loading the test turbine to measure the torque. The weighing pan, pulley and spring balance are connected by rope of $6 \mathrm{~mm}$ diameter.

The three types of turbines considered for the experimentation as given below.

1. Savonoius turbine with $\alpha=1, \beta=0.16$ ( $\mathrm{D}=600 \mathrm{~mm}$, $\mathrm{H}=600 \mathrm{~mm}$ ) with two, three and four blades.

2. Darrieus turbine with $\alpha=1$ and blade airfoil NACA0021with two and three blades.

3. Hybrid turbine with $\alpha=1$ combined with Savonius and Darrieus fitted Savonius blades centrally with same height of Darrieus blades with two and three blades.

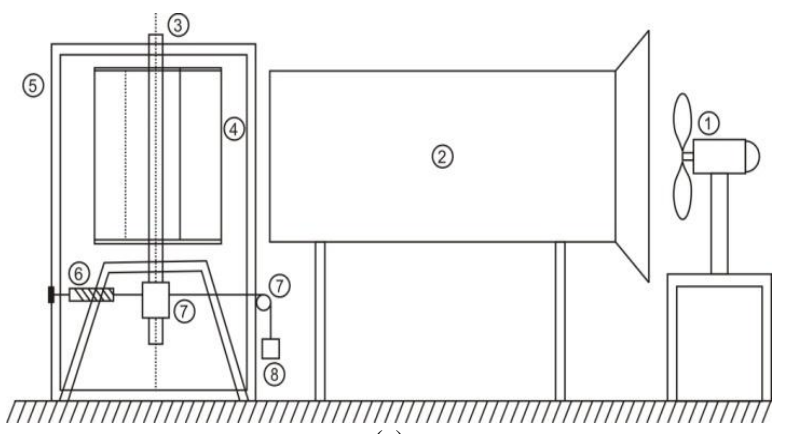

(a)

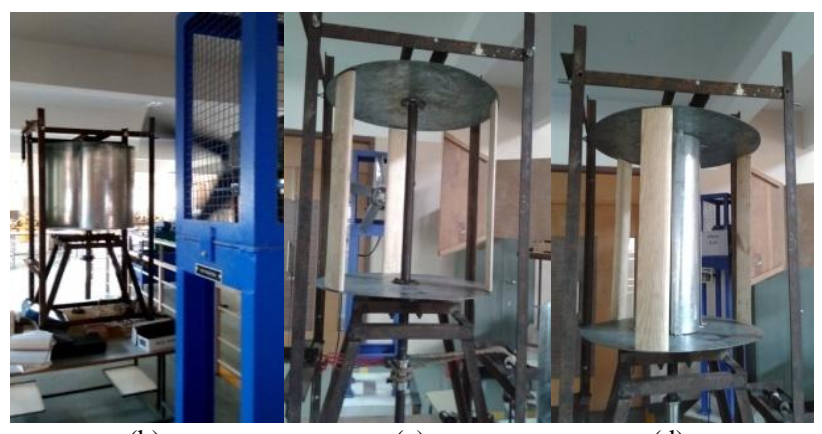

(b)

Fig. 4. (a) Schematic diagram of experimental setup, (b) Photograph of Savonius rotor, (c) Photograph of Darrieus rotor, (d) Photograph of hybrid turbine.

\section{RESULTS AND DISCUSSION}

\section{A. Results and Discussion of Savonius Turbine}

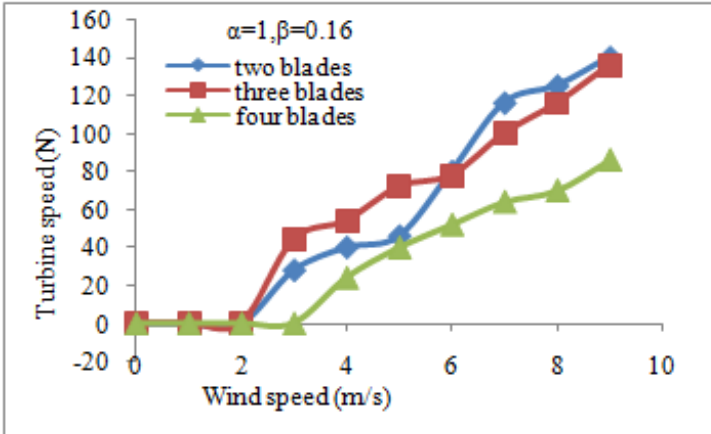

Fig. 5. Variation of turbine speed with wind speed for Savonius rotor with two, three and four blades.

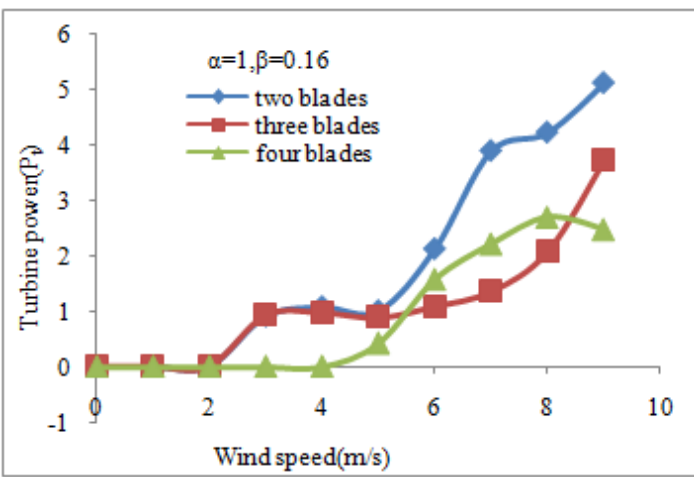

Fig. 6. Variation of turbine power with wind speed for Savonius rotor with two, three and four blades.

Fig. 5 and Fig. 6 represent the variation of turbine speed and power with wind speed for the Savonius rotors. The three blades rotor gives higher speed and higher turbine power at low wind speed 2-6 m/s compared to two and four blades. In two blade Savonius turbine, one blade is directly exposed for maximum work done, which is perpendicular with wind direction. However impact of air on convex portion of other blade gives maximum resistance compared with two such blades at different angle for three blades. For four blades the frictional losses are more compared with two and three blades of Savonius turbine. Therefore three blades Savonius rotor gives higher coefficient of power at low wind speed 2-5.5 m/s than to two and four blades as shown in Fig. 7. 


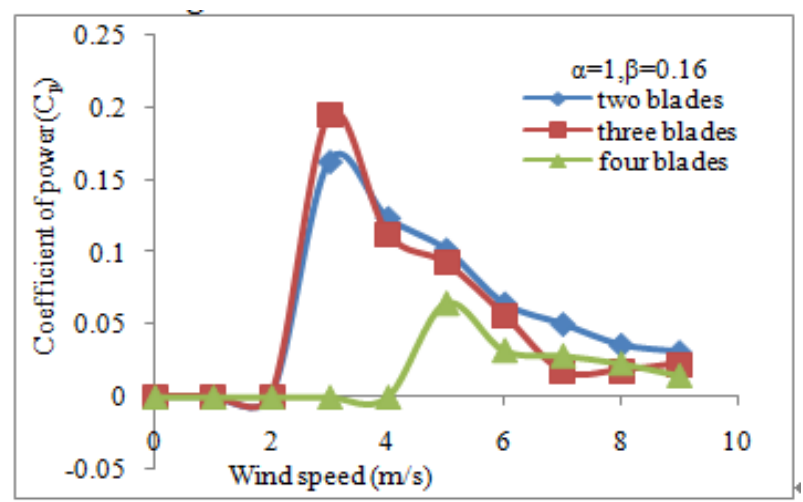

Fig. 7. Variation of coefficient of power with wind speed for Savonius rotor with two, three and four blades.

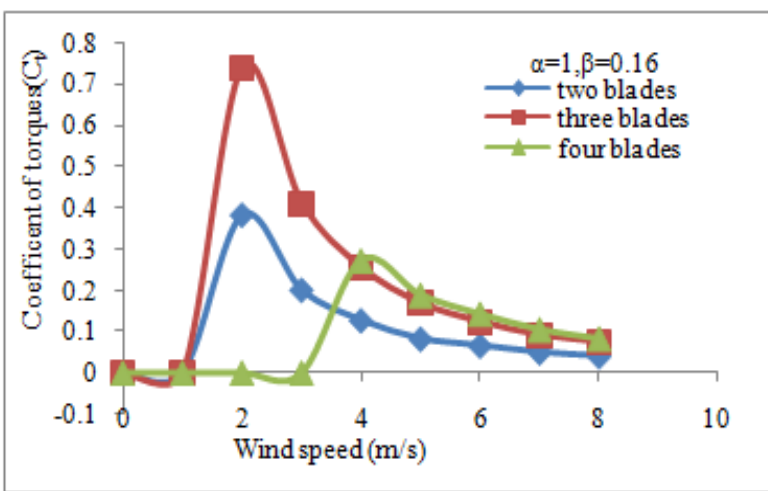

Fig. 8. Variation of coefficient of torque with wind speed for Savonius rotor with two, three and four blades.

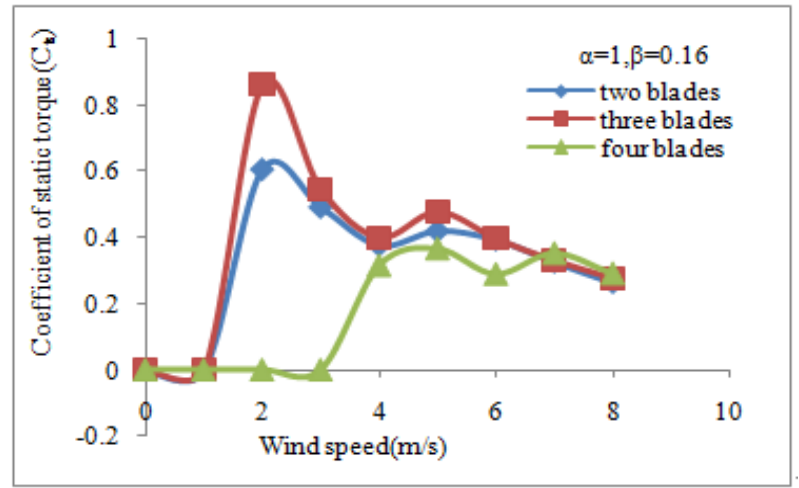

Fig. 9. Variation of coefficient of static torque with wind speed for Savonius rotor with two, three and four blades.

Fig. 8 and Fig. 9 show the variation of coefficient of static torque and coefficient of torque. The static torque is the torque affected on rotor to stop its rotation and keep it stand still. The static torque coefficient can be calculated by Eq. 11 . It is observed from the Fig. 9 that, the static torque coefficient of three blade rotor is more than the two and four blades rotor at entire range of wind speed $(1.5-8 \mathrm{~m} / \mathrm{s})$.

\section{B. Results and Discussion of Darrieus Turbine}

Fig. 10 to Fig. 12 represent the variation of turbine speed, turbine power and coefficient of power with wind speed for the Darrieus turbine with three and four aerofoil blades. The coefficient of power of Darrieus turbine with four blades is 0.21 . It is clear from the graph that the Darrieus turbine with four aerofoil blades is more efficient than the three aerofoil blade in the range of wind speed form $5 \mathrm{~m} / \mathrm{s}$ to $9 \mathrm{~m} / \mathrm{s}$. This may be because of increasing the number of blades from three to four results in full utilization of incoming wind. From the results it is also seen that the Darrieus turbine is more efficient than the Savonius turbine but it is not self-started at low wind speed $0-5 \mathrm{~m} / \mathrm{s}$.

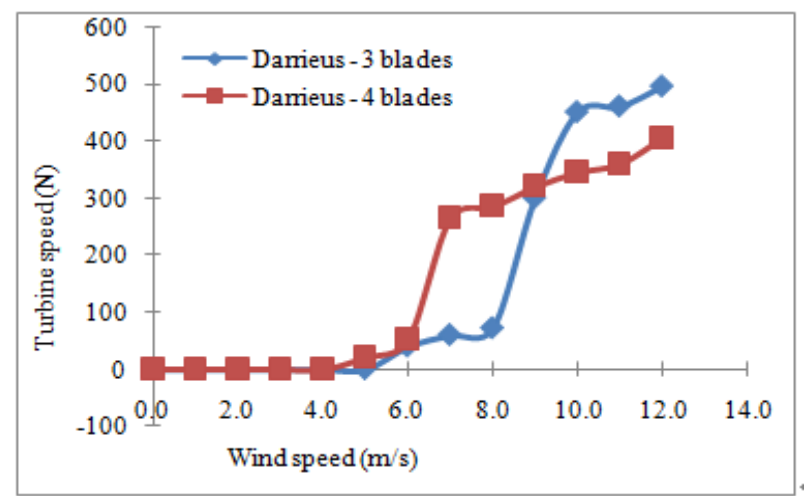

Fig. 10. Variation of turbine speed with wind speed for Darrieus turbine with three and four blades.

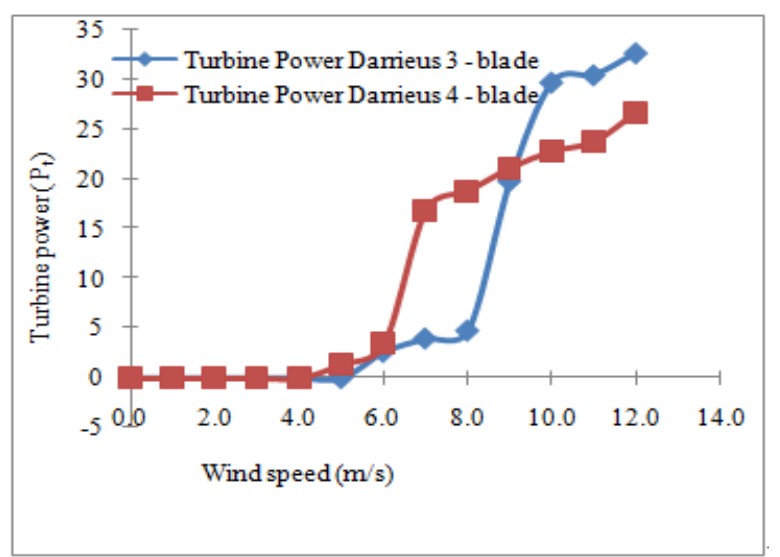

Fig. 11. Variation of turbine power with wind speed for Darrieus turbine with, three and four blades.

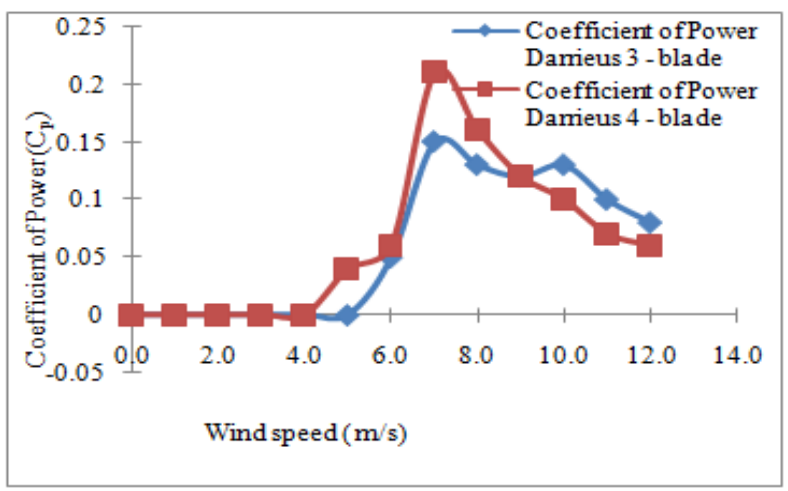

Fig. 12. Variation of coefficient of power with wind speed for Darrieus turbine with three and four blades.

\section{Results and Discussion of Hybrid Turbine}

Fig. 13 to Fig. 15 represent the variation of turbine speed, turbine power and coefficient of power with wind speed for the Hybrid turbine combined with Savonius and Darrieus rotor with various combinations of blades. It can be seen from the Fig. 13 that the hybrid turbine with 3 Savonius and 4 aerofoil blades turbine speed is more than the other combination in the range of wind speed $2-5 \mathrm{~m} / \mathrm{s}$. Turbine power of hybrid turbine with combination of 3 Savonius and 3 aerofoil is quite good at wind speed range $2-8 \mathrm{~m} / \mathrm{s}$ compared to other combinations as shown in Fig. 14. Also we can see 
from the Fig. 15 that the coefficient of power of 3 Savonius and 3 airfoil is 0.23 at low wind speed and it is higher than the other combinations of this turbine and also higher than the individual Savonius and Darrieus turbine. The hybrid turbine with 3 Savonius and 3 airfoil blades is recommended for house hold application.

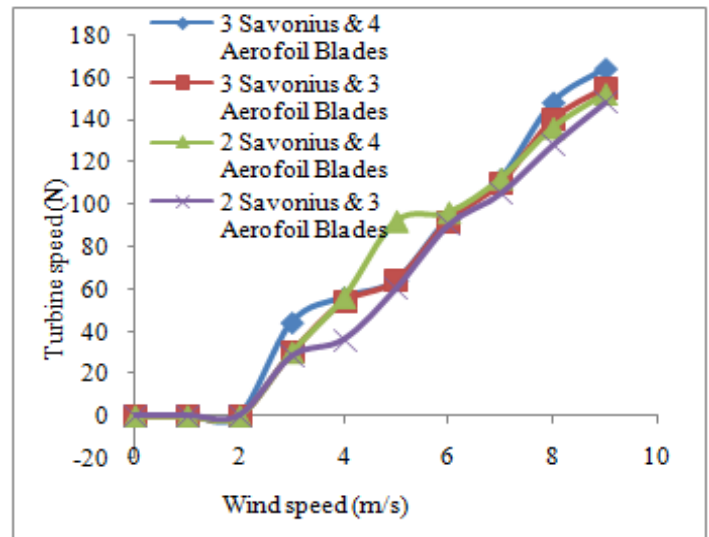

Fig. 13.Variation of turbine speed with wind speed for Hybrid turbine of various combinations.

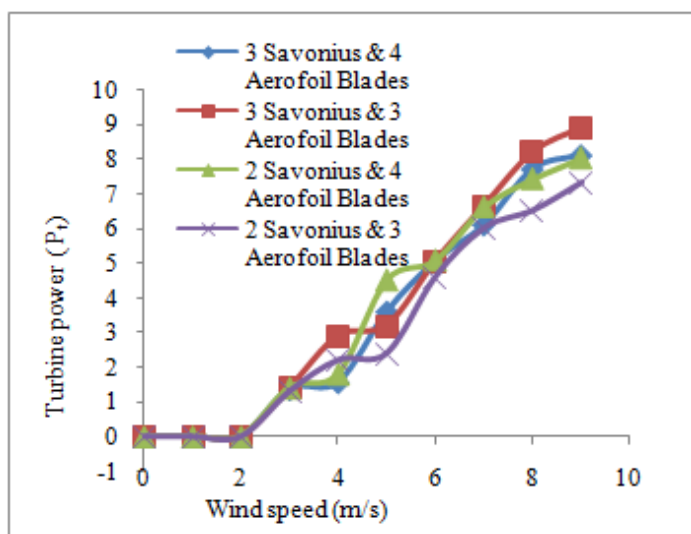

Fig. 14. Variation of turbine power with wind speed for Hybrid turbine with various combinations.

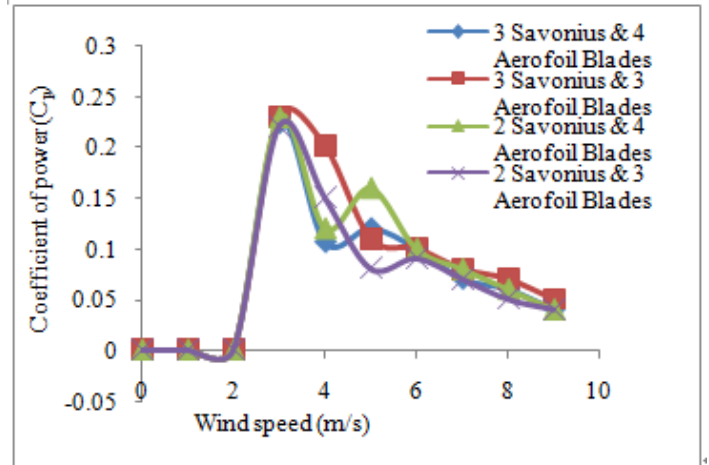

Fig. 15. Variation of coefficient of power with wind speed for Hybrid turbine with various combinations.

\section{CONCLUSIONS}

In the present work Savonius, Darrieus and Hybrid turbine with different combination of two, three and four blades with aspect ratio $\alpha=1$ and overlap ratio $\beta=0.16$ are tested experimentally to determine the size, geometries of these turbines for limited power generation for house hold applications. The following conclusions are drawn from the present study.

Coefficient of power of the Savonius turbine is 0.19 at wind speed $3 \mathrm{~m} / \mathrm{s}$ and it suddenly decreases as wind speed increases. Savonius turbine with three blades performs better at low wind speed than two and four blades Savonius turbine.

Darrieus turbine is not self-started at low wind speed but it is more efficient than the Savonius turbine in the range of wind speed 5-9 m/s. Coefficient of power of Darrieus turbine with four aerofoil blades is 0.21 at $7 \mathrm{~m} / \mathrm{s}$ wind speed.

Coefficient of power of hybrid turbine is 0.23 at low wind speed which is higher than the Savonius and Darrieus turbine. Generally wind speed range $0-6 \mathrm{~m} / \mathrm{s}$ is available at the rural and urban areas. Since the Hybrid turbine coefficient of power is more than the Darrieus and Savonius turbine at low wind speed it is suitable and recommended for house hold application for power generation in rural and urban area. The drawback of self starting for Darrieus turbine is overcome by Hybrid turbine combined Darrieus with Savonius blades.

\section{NOMENCLATURES}

$A=$ Swept area $\left(\mathrm{m}^{2}\right)$

$D=$ Diameter of turbine (m)

$H=$ Height of turbine (m)

$d=$ Diameter of blade $(\mathrm{m})$

$\rho=$ Density of air $\left(\mathrm{k}_{\mathrm{g}} / \mathrm{m}^{3}\right)$

$V=$ Wind velocity $(\mathrm{m} / \mathrm{s})$

$T=$ Turbine or mechanical torque $(\mathrm{Nm})$

$T_{w}=$ Wind torque $(\mathrm{Nm})$

$\omega=$ Angular speed $(\mathrm{rad} / \mathrm{s})$

$N=$ Shaft speed (rpm)

$P_{w}=$ Wind power available (Watts)

$P_{m}=$ Turbine power output (Watts)

$\mu=$ Dynamic viscosity of air $(\mathrm{kg} / \mathrm{m})$.

\section{REFERENCES}

[1] S. G. Gawade and D. S. Patil, "Comparative study of a single stage Savonius with a combined Savonius-three bladed Darrieus," International Journal for Technological research in Engineering, vol. 2, issue 6, February 2015.

[2] S. J. Savonius, "The S - rotor and its application," Mech Eng. vol. 53, pp. 333-338, 1931.

[3] M. H. Ali, "Experimental comparison study for Savonius wind turbine of two and three blades at low wind speed," International Journal of Modern Engineering Research, vol. 3, issue 5, 2013.

[4] B. D. Altan and M. Atilgan, "A study on increasing the performance of Savonius wind rotors," Journal of Mechanical Science and Technology, vol. 26, ED-5, pp. 1493-1499, 2012.

[5] M. A. Kamoji, S. B. Kedare, and S. V. Prabhu, "Experimental investigations on single stage modified Savonius rotor," Applied Energy, vol. 86, pp. 1064-1073, 2008.

[6] U. K. Saha, S. Thotla, and D. Maity, "Optimum design configuration of Savonius rotor through wind tunnel experiments," Journal of Wind Engineering and Industrial Aerodynamics, vol. 96, pp. 1359-1375, 2008

[7] J. L. Menet, "A double-step Savonius rotor for local production of electricity: A design study," Renewable Energy, vol. 29, pp 1843-1862, 2004.

[8] M. A. Kamoji, S. B. Kedare, and S. V. Prabhu, "Performance tests on helical Savonius rotors," Renewable Energy, vol. 34, pp. 521-529, 2009.

[9] M. Abid, K. S. Karimov, H. A. Wajid, F. Farooq, H. Ahmed, and O. H. Khan, "Design, development and testing of a combined Savonius and Darrieus vertical axis wind turbine," Iranica Journal of Energy and Environment, vol. 6, ED-1, pp. 1-4, 2015.

[10] T. G. Abu-El-Yazied, A. M. Ali, M. S. Al-Ajmi, and I. M. Hassan, "Effect of number of blades and blade chord length on the performance of Darrieus wind turbine," AJMEA, vol. 2, ED-1, pp. 16-25, 2015. 
[11] S. Brusca, R. Lanzafame, and M. Messina, "Design of a vertical axis wind turbine: How the aspect ratio affects the turbine performance," International Journal of Energy Environ Engineering, vol. 5, pp. 33-340, 2014.

[12] R. Gupta, A. Biswas, and K. K. Sharma, "Comparative study of a three-bucket Savonius rotor with a combined three-bucket Savonius-three-bladed Darrieus rotor," Renewable Energy, vol. 33, pp. 1974-1981, 2008.

[13] R. Howell, N. Qin, J. Edward, N. Durrani, "Wind tunnel and numerical study of a small vertical axis wind turbine," Renewable Energy, vol. 35 , pp. 412-422, 2010.

[14] F. Feng, S. M. Li, Y. Li, and D. Xu, "Torque characteristic simulation on small scale combined type vertical axis wind turbine," Physics Procedia, vol. 24, pp. 781-786, 2012.

[15] S. M. Rassoulinejad-Mousavi, M. Jamil, and M. Layeghi, "Experimental study of a combined three bucket $\mathrm{H}$ - Rotor wind turbine,” World applied Sciences Journal, vol. 28, pp. 205-211, 2013.

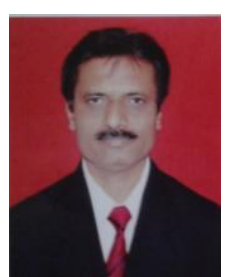

Ramesh Krishnat Kavade was born on Feb. 7, 1966, graduated in mechanical engineering from Govt. College of Engineering, Karad, Maharashtra, India, in 1988. He did his post-graduation (M.E.) in mechanical engineering with specialization in heat power engineering at College of Engineering, Pune. He is a research scholar and doing research on vertical axis wind turbine under the guidance of Dr. P. M.
Ghanegaonkar at Dr. D. Y. Patil Institute of Engineering and Technology, Pimpri, Pune, under the Savitribai Phule Pune University, Pune. He is currently working as an Associate Professor in mechanical engineering at Dr. D. Y. Patil Institute of Engineering and Technology, Pimpri, Pune.

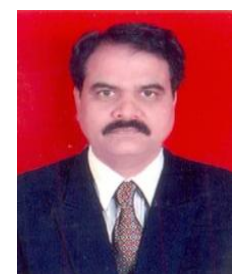

Pravin M. Ghanegaonkar was born on August 21, 1963, graduated in mechanical engineering from the College of Engineering, Pune, Maharashtra, India, in 1984. He did his post-graduation (M. Tech.) degree in mechanical engineering with specialization in thermal and fluid engineering at IIT, Bombay, in 1986. The author has obtained his $\mathrm{PhD}$ degree in 2005 from Pune University, Pune. His area of interest is thermodynamics, fluid mechanics, heat transfer and computational fluid dynamics (CFD). He has been engaged in active research in the field of computational fluid dynamics (CFD), fluid mechanics and heat transfer. He has published 25 research papers in various national and international journals. He has worked as Principal at D. Y. Patil College of Engineering, Akurdi, Pune and Sinhagad College of Engineering, Narhe, Pune, for two and three years respectively. Presently, he is working as the Dean Academics and Professor in mechanical engineering at Dr. D. Y. Patil Institute of Engineering and Technology, Pimpri, Pune. He is the chairman, board of studies in Automobile Engineering at Savitribai Phule Pune University, Pune. 